\title{
Códigos de práticas: uma proposta de documentos técnicos de referência de boas práticas para a construção de edifícios no Brasil
}

\author{
Codes of Practice: a proposal of technical reference \\ documents of good practices for building construction in \\ Brazil
}

\section{Fabiana da Rocha Cleto \\ Francisco Ferreira Cardoso \\ Cláudio Vicente Mitidieri Filho \\ Vahan Agopyan}

\section{Resumo}

Fabiana da Rocha Cleto Departamento de Engenharia de Construção Civil, Escola Politécnica Universidade de São Paulo Av. Prof. Almeida Prado, 523, Prédio 24, Butantã

São Paulo - SP - Brasil CEP 05508-901

Tel.: (11) $3767-4981$ E-mail: fabiana.cleto@usp.br

Francisco Ferreira Cardoso Departamento de Engenharia de Construção Civil, Escola Politécnica Universidade de São Paulo Av. Prof. Almeida Prado, 83, Travessa 2, Cidade Universitária São Paulo - SP - Brasil CEP 05508-900 Tel. (11) 3091-5469 E-mail: francisco.cardoso@poli.usp.br

Cláudio Vicente Mitidieri Filho Instituto de Pesquisas Tecnológicas do Estado de São Paulo Caixa-Postal 0141 Av. Prof. Almeida Prado, 532, Butantã São Paulo - SP - Brasi CEP 05508-901

Tel.: (11) 3767-4256 E-mail: claumit@ipt.br

Vahan Agopyan Departamento de Engenharia de Construção Civil, Escola Politécnica Universidade de São Paulo Tel.: (11) 3091-5364 E-mail: vahan.agopyan@poli.usp.br

Recebido em 25/10/10 Aceito em 25/05/11

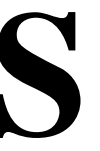

istemas para elaboração de documentos técnicos de referência nacional que consolidam as boas práticas do processo de produção de edifícios existem em diversos países, sendo utilizados diferentes nomes, tais como Building Codes nos Estados Unidos, Canadá e Austrália, Codes of Practice na Inglaterra e Documents Techniques Unifiés na França. No Brasil, entretanto, esse tema é recente, mas o setor da construção de edifícios tem-se conscientizado da importância de se formalizarem e harmonizarem as melhores práticas desde o projeto até a execução, uso e manutenção dos edifícios. O objetivo deste artigo é propor uma sistemática para a elaboração de documentos técnicos de referência de boas práticas para a construção de edifícios no Brasil. A proposta foi feita com base em ampla revisão bibliográfica, principalmente no que se refere experiências internacionais bem sucedidas, e da análise de documentos produzidos no Brasil e no exterior. A mesma foi submetida à análise e validação junto a entidades do setor da construção de edifícios por meio de reuniões e de um workshop. As principais contribuições deste trabalho refere-se ao modelo conceitual proposto, assim como no arranjo institucional necessário para a produção de códigos de prática no pais.

Palavras-chave: Boas práticas. Documentos técnicos de referência. Códigos de práticas.

\section{Abstract}

Systems for the drawing up of national technical reference documents that consolidate good practices of the building production process exist in many countries. These documents receive different names, such as Building Codes, in the USA, Canada and Australia, Codes of Practice, in the U.K., and Documents Techniques Unifiés, in France. In Brazil, although this is a new issue, the construction sector is becoming more aware of the importance of formalizing and harmonizing best practices, from the design to the execution, use and maintenance of buildings. The aim of this article is to propose a system for the production of codes of practice for building construction in Brazil. This investigation was based on a broad literature review, focused on successful international experiences, as well as on the analysis of documents produced in Brazil and abroad. The proposed model was submitted to a technical analysis and validation by the organizations from the building sector through meetings and a workshop. The main contributions of this study are concerned with the proposed conceptual model, and with the institutional arrangement that is necessary for the production of codes of practice in Brazil.

Keywords: Good practices. Technical reference documents. Codes of practices. 


\section{Introdução}

O termo "boas práticas" é uma adaptação da expressão derivada do inglês "best practices", a qual denomina técnicas identificadas como as melhores para realizar determinadas atividades, podendo-se definir também a melhor forma de atuar dos profissionais que as executam. As boas práticas são consagradas para uma atividade quando existe um consenso a respeito dos modos mais eficientes e eficazes de realizá-la, segundo procedimentos comprovados ao longo do tempo por uma quantidade significativa de pessoas experientes no assunto.

Um documento que formaliza boas práticas tornase uma referência e contribui para a melhoria da qualidade de atividades e seus resultados, podendo ser incorporado a uma estrutura de regulamentação e tornar-se não somente orientativo, mas também um instrumento regulatório e/ou contratual de empresas, instituições ou de um setor.

Entretanto, consagrar as boas práticas não é algo simples. No caso deste artigo, o escopo do tema estudado, relativo às boas práticas, está limitado ao setor da construção de edifícios. Assim, tanto as especificações quanto os processos utilizados com sucesso pelos atores desse setor devem ser definidos em consenso e comprovados por meio de testes empíricos, ensaios laboratoriais ou pela experiência prática adquirida.

Para formalizar um conjunto de boas práticas para a construção de edifícios é necessário criar um sistema que tenha esse objetivo e que forneça meios para concretizá-lo, como o ocorrido em diversos países. Esse conjunto de boas práticas é identificado de maneira distinta em cada país; nos países anglo-saxões é denominado codes of practices, em países como Estados Unidos, Canadá e Austrália de building codes, entre outros. Também existem diferenças no processo que regulamenta esses conjuntos de boas práticas nos países, que vão desde sua integração ao sistema normativo oficial ou seu uso como referência técnica complementar até, às vezes, para apoio aos sistemas de seguro da construção.

Todavia, mesmo considerando as peculiaridades de cada sistema, os resultados de sua implantação foram positivos, não havendo dúvida de que a existência de um conjunto de boas práticas contribui para orientar o setor da construção de edifícios, balizar as relações contratuais e melhorar a qualidade das obras e o desempenho dos edifícios.

Contribui-se para a orientação desse setor ao formalizar seu conhecimento, uma vez que grande parte desse conhecimento ainda é tácito, e não explícito, encontrando-se disperso e sem registros, informalmente entre profissionais. Além disso, o conhecimento passa a ser harmonizado e disseminado de forma eficiente para esses profissionais. Quanto às relações contratuais, um conjunto de boas práticas é um instrumento de referência para contratantes e contratados, sejam empresas projetistas, construtoras, seguradoras, responsáveis pelo acompanhamento e licenciamento de obras, etc. Outrossim, o fato de se utilizarem soluções consagradas e boas práticas nas etapas de projeto, execução e controle das obras contribui para que o edifício tenha melhor qualidade e atenda aos principais requisitos de desempenho.

Os impactos e os benefícios da criação e utilização de um conjunto de boas práticas na construção de edifícios demonstram que o tema é uma contribuição importante e necessária para a modernização desse setor no país. Portanto, o objetivo do artigo é propor os principais aspectos para a elaboração de documentos técnicos de referência de boas práticas para a construção de edifícios no Brasil. Propõe-se um modelo de documento a ser usado como referência para a descrição das boas práticas e um modelo de estrutura e funcionamento de um sistema a ser criado para elaborar tais documentos. O modelo de documento proposto foi aplicado a determinado elemento construtivo, como experiência piloto.

O método de pesquisa considera a revisão bibliográfica (que inclui referências de países estrangeiros e iniciativas nacionais), com caráter descritivo, por meio da análise de documentos técnicos, com propósito exploratório, de natureza qualitativa, e a experiência profissional dos autores. A proposta foi analisada e validada por meio de reuniões com representantes do setor da construção de edifícios, no decorrer de 2009, na sede da Federação das Indústrias do Estado de São Paulo (FIESP), e pela realização de um workshop, em novembro do mesmo ano, no Sindicato das Empresas de Compra e Venda de Imóveis Residenciais e Comerciais de São Paulo (SECOVI-SP). Participaram do workshop aproximadamente 50 representantes de associações, sindicatos, instituições, agentes promotores e financeiros da habitação e empresas privadas do setor, com representatividade nacional.

\section{Sistemas para a elaboração de documentos de boas práticas}

Em diversos países, o setor da construção de edifícios possui sistemáticas para a elaboração de 
documentos técnicos de referência, unificados nacionalmente, que consolidam boas práticas para o processo de produção de edifícios, além de balizarem contratos e licitações, em determinados casos. Algumas iniciativas relativas ao tema começam a surgir no Brasil, uma vez que esse setor está se conscientizando da necessidade e importância de se formalizar o conhecimento e de harmonizar as melhores práticas de projeto, execução, controle, uso e manutenção dos edifícios (IPT, 2010; EPUSP, 2010).

Foram estudadas diversas sistemáticas existentes, a estrutura e o mecanismo de operacionalização e governança de cada uma. O artigo apresenta os principais tópicos das sistemáticas do Canadá, Estados Unidos, Austrália e França, bem como um cenário de iniciativas nacionais já implantadas, visando subsidiar a proposta de um sistema para o Brasil. Devido à limitação do escopo da pesquisa, alguns países não tiveram maior detalhamento de suas sistemáticas, porém não são menos importantes. É o caso do sistema inglês, o qual foi um dos primeiros do mundo, com a elaboração dos Codes of Practices, documentos identificados pelo prefixo CP. Ao longo dos anos, a maioria dos Codes of Practices foi designada como normas técnicas da Inglaterra, recebendo também o prefixo BS, de British Standards. Atualmente, conforme BSI (2011), há aproximadamente 20 documentos apenas identificados como $\mathrm{CP}$, que podem ser usados, mas não são mantidos por nenhuma comissão da British Standards Institution. Assim, o Code of Practice corresponde, hoje, a um tipo de norma inglesa que complementa os demais: especificação, método/procedimento, terminologia, classificação e guias.

Percebe-se que é importante contextualizar os diferentes papéis dos documentos de boas práticas em cada país. Por exemplo, no Canadá, assim como no caso inglês, os conjuntos de boas práticas se prestam prioritariamente para apoio à operação do sistema de seguro, assim como também na França, ainda que neste país tenham outras funções e que seu papel legal seja mais extenso. Já nos Estados Unidos, a instituição responsável pela elaboração de seu building code propõe-se fundamentalmente a embasar o processo de licenciamento e acompanhamento de obras pelo setor público e governamental.

O documento de referência do Canadá é o National Building Code of Canadá (NBC), desenvolvido pela Canadian Commission on Building and Fire Codes (CCBFC). Essa comissão é financiada pela venda dos documentos e pelo National Research Council, sendo a responsável por supervisionar a atuação dos diversos comitês e grupos de trabalho.
Segundo NRC (2005), o sistema canadense é estruturado de forma que são os próprios membros dos comitês que estabelecem o conteúdo dos documentos. Os especialistas da cadeia produtiva, do setor de regulamentações técnicas e dos grupos de interesse representam os subsetores relevantes da construção e as áreas geográficas do país, sendo consensual o conteúdo dos documentos. O objetivo do NBC é propiciar segurança estrutural, segurança ao fogo, acessibilidade e outros requisitos de desempenho para edifícios novos, demolição ou reabilitação.

Já nos EUA existiam três building codes, elaborados por diferentes instituições e adotados em distintas regiões, conforme ICBO (1994):

(a) National Building Code, elaborado pelo Building Officials and Code Administrators (BOCA);

(b) Standard Building Code, sob responsabilidade do Southern Building Code Congress International (SBCCI); e

(c) Uniform Building Code, desenvolvido pela International Conference of Buildings Officials (ICBO).

Na década de 1990, essas instituições reuniram-se e criaram o International Code Council (ICC), no intuito de se ter um sistema abrangendo todo o país. O ICC elaborou o International Building Code (IBC), documento de caráter nacional que reúne aspectos dos documentos anteriores.

No sistema dos EUA são formados comitês com representantes de code oficials, projetistas, consultores, associações comerciais, construtores, empreiteiros, fabricantes, fornecedores, agências governamentais e demais interessados (INTERNATIONAL..., 2000). Porém, é importante destacar que o IBC é adotado nos Estados Unidos como complemento à legislação local pela maioria dos condados (no Brasil, denominados municípios), cumprindo a função de facilitar as inspeções das obras. Além disso, tal documento tem papel fundamental no sistema de licenciamento, em contraposição ao papel dos sistemas dos demais países analisados.

Outra peculiaridade dos EUA é a existência de dezenas de outros conjuntos de boas práticas mais específicos, como os do National Fire Protection Association (NFPA). Esses demais conjuntos são complementares ao IBC e, em geral, voltam-se à orientação de aspectos específicos.

Outra sistemática estudada foi a da Austrália. Seu documento técnico de referência foi elaborado, pois, em determinado momento, se considerou desejável que todos os australianos tivessem o 
mesmo nível de segurança e conforto, fazendo-se necessária a cooperação para criar um código unificado com requisitos de desempenho e padrões técnicos para projeto e execução de edifícios (ABCB, 1996). Assim foi desenvolvido o Building Code of Australia (BCA), sob a responsabilidade do Australian Building Codes Board (ABCB), o qual é constituído por representantes de cada estado e território, do governo local (Australian Local Governament Association - ALGA) e da indústria da construção. O conteúdo do documento é desenvolvido pelos comitês específicos do $\mathrm{ABCB}$, os Building Codes Committee. Ressalta-se que cada estado e território tem o poder de decidir quais aspectos do BCA são necessários para suas respectivas regiões. Segundo ABCB (1996), as boas práticas e soluções prescritas no BCA facilitam o projeto e a aprovação de edifícios que empregam processos tradicionais, pois consideram que, se elas forem seguidas, o edifício estará de acordo com os requisitos de desempenho exigidos. Pode-se, porém, adotar uma solução alternativa, desde que se comprove que tais exigências são satisfeitas.

No caso da França, existiam diversos documentos técnicos usados por contratantes de obras, empresas de habitação para aluguel social, de controle tecnológico, arquitetos, seguradoras e sindicatos. Mas em 1957 foi concluído um processo de consolidação desses documentos, originando o Sistema DTU - Documents Techniques Unifiés, sob a responsabilidade do Centre Scientifique et Technique du Bâtiment (CSTB). O Sistema DTU é composto de uma série de documentos que registram as boas práticas para a construção de edifícios (CENTRE..., 2002). Desde então, os contratos para execução de obras ou serviços na França contém: cláusulas técnicas gerais, as quais se referem a um conjunto de DTUs; e cláusulas técnicas particulares, que descrevem as especificidades do empreendimento. Além de constarem dos contratos, os DTUs fazem parte dos editais de licitação de construtoras.

Destaca-se que os DTUs, na medida em que foram sendo consolidados no setor da construção de edifícios, passaram a integrar a regulação normativa da França. Como consequência da unificação europeia, a partir de 1993, os documentos obtiveram status de normas técnicas e foram incorporados gradativamente pela Association Française de Normalisation (AFNOR). Nesse processo de transição, gerenciado pelo CSTB por delegação da AFNOR, cada DTU passou por votação, visando ao consenso. Barros (2000) destaca que esse processo é fundamentado na existência de comissões, das quais participam diferentes agentes do setor: fabricantes, representantes do Estado, arquitetos, engenheiros, consumidores, laboratórios, etc. Atualmente, grande parte dos DTUs constitui-se em Normas Francesas (NF), sendo denominados NF-DTU.

Já em relação ao cenário brasileiro, ainda não existe um sistema efetivamente implantado para a elaboração de boas práticas aplicadas ao setor da construção de edifícios. Alguns mecanismos institucionais e de governança existem para produzir documentos técnicos de referência, porém são sistemas que não guardam semelhança de objetivos, aplicação ou resultados com relação aos que existem para o desenvolvimento de codes e similares em outros países.

Como exemplo de estrutura para a elaboração de documentos de referência, com a formação de comitês técnicos e comissões que contemplem diferentes agentes da cadeia produtiva, o Brasil possui algumas iniciativas de âmbito nacional que desenvolvem documentos para a construção de edifícios, mas com objetivos distintos dos documentos de boas práticas. O estudo dessas iniciativas serve apenas para contextualizar o que já existe no cenário nacional, analisando, inclusive, a interface que teriam com o sistema a ser proposto.

Por exemplo, em 2007, foi criado um sistema para respaldar o uso de inovações tecnológicas no setor da construção de edifícios do Brasil, denominado Sistema Nacional de Avaliações Técnicas (SINAT) de produtos inovadores (PBQP-H, 2007). Esse sistema teve como base o modelo já existente na França, também coordenado pelo CSTB, que elabora documentos como o Avis Téchnique (ATEC) para produtos inovadores. No caso do Brasil, esse sistema foi integrado ao cenário nacional ao ser vinculado ao Programa Brasileiro de Qualidade e Produtividade do Habitat (PBQP$\mathrm{H})$, existente no âmbito do Ministério das Cidades, do Governo Federal.

Outros países também possuem sistemas que desenvolvem documentos similares para inovação, como o Reino Unido, que tem o Agrément Certificate, concedido pelo British Board of Agreement (BBA), e a Austrália, que possui o Appraisal Agreement, concedido pelo Australia's Commonwealth Scientific and Industrial Research Organisation (CSIRO). Observa-se que esses países possuem um sistema e um documento específico para tratar práticas inovadoras e outro para práticas consagradas; entretanto, a estrutura proposta para a elaboração de documentos de referência guarda algumas semelhanças, como o caso francês, que teve a iniciativa do CSTB para ambas as situações. No Brasil, como visto, o PBQP-H já possui um sistema nacional para 
práticas inovadoras, porém não existe ainda um sistema nacional para práticas consagradas. Já houve, entretanto, manifestação recente de interesse por parte do PBQP-H em participar do desenvolvimento desse sistema complementar.

Outro sistema nacional é o adotado pela Associação Brasileira de Normas Técnicas (ABNT), a qual tem a atribuição fundamental de ser a responsável oficial pela elaboração de Normas técnicas no Brasil, função esta reconhecida pelo Sistema Nacional de Metrologia, Normalização e Qualidade Industrial (SINMETRO). A ABNT possui um conselho técnico que reúne os Comitês Brasileiros representativos de subsetores da construção, os quais abrigam as comissões de estudos responsáveis pela elaboração e revisão das normas (ABNT, 2009). A Comissão de Estudo elabora um texto-base em consenso, o qual é submetido à apreciação da sociedade por meio de consulta nacional e, uma vez aprovado, dá origem a uma norma brasileira.

Observa-se que, assim como os sistemas focados nos documentos de boas práticas, essa sistemática tem o objetivo também de elaborar documentos técnicos de referência por consenso e com validade nacional, porém com uma série de diferenças. As normas têm um padrão específico de conteúdo que não permite, por exemplo, considerar aspectos administrativos e de garantias e responsabilidades. Tais aspectos são contemplados nos DTUs franceses e nos building codes dos EUA e do Canadá. Portanto, os documentos de boas práticas podem suprir tais lacunas no Brasil.

Além disso, nas Normas ABNT, nem sempre há preocupação de se reunirem em um único documento as diversas etapas do processo de produção de um elemento construtivo, como é feito nos DTUs. Nos documentos de boas práticas isso pode ser feito, evitando conflitos de informações e facilitando a visão sistêmica. Nesses documentos, são compiladas as melhores práticas consagradas em todas as etapas da construção de edifícios, desde seu projeto até sua manutenção, podendo propor, inclusive, soluções construtivas que já tenham seu desempenho comprovado.

Outra diferença é que, apesar de a iniciativa de se elaborarem normas brasileiras ser voluntária, seu cumprimento, quando em vigor, tem caráter obrigatório. Isso porque, embora não sejam leis, as normas técnicas têm implicações de natureza jurídica e comercial, como, por exemplo, em situações que tratam de dever ético profissional, contratual ou legal (quando a lei assim o determina). Já os documentos de boas práticas são complementares às Normas ABNT, porém sem ter, de início, um caráter obrigatório, podendo ser acessados gratuitamente pelo setor e utilizados como orientação. Posteriormente, podem fazer parte de contratos entre agentes do setor e, futuramente, integrar-se ao sistema de normalização, como o ocorrido na França e na Inglaterra.

\section{Modelos de documentos de boas práticas para a construção de edifícios}

São apresentadas a seguir as principais características dos documentos estrangeiros estudados, bem como de alguns documentos nacionais que, resguardados os respectivos contextos e limitações, possuem aspectos relacionados às boas práticas para a construção de edifícios.

O National Building Code of Canada teve sua primeira edição em 1941. Conforme NRCC (2005), o documento possui dois volumes com três divisões cada. No primeiro, a Divisão A apresenta objetivo, escopo e aplicação do documento, bem como requisitos qualitativos de desempenho para análise de soluções inovadoras. A Divisão B estabelece níveis mínimos de desempenho (segurança estrutural e ao fogo, acessibilidade, sistemas prediais, etc.), e práticas consagradas para construção de casas térreas e de edifícios de até três pavimentos. A Divisão $\mathrm{C}$ contém aspectos administrativos, de planejamento e de projetos. $\mathrm{O}$ segundo volume é apenas um apêndice. O NBC é revisado continuamente para incorporar novas práticas de construção, tecnologias, materiais, políticas sociais e necessidades da sociedade canadense, considerando outras possíveis especificações de projeto e execução. Seu conteúdo foi harmonizado com algumas normas norte-americanas devido à globalização e ao livrecomércio.

Inclusive, em se tratando dos EUA, o documento International Building Code teve sua primeira versão, em 1997, elaborada por cinco subcomitês com representantes do BOCA, do SBCCI e do ICBO. Em 2000, com o ICC, a nova versão teve a participação de usuários, indústrias e alguns agentes do setor. Conforme ICC (2000), o IBC está subdividido em 35 capítulos e dez anexos, que estabelecem parâmetros mínimos para os edifícios, com práticas prescritivas e requisitos de desempenho (como resistência ao fogo, eficiência energética, segurança estrutural, conforto térmico e acessibilidade), os quais podem ser utilizados de acordo com as leis locais. O documento contempla boas práticas para diferentes etapas da obra 
(projeto, execução, etc.) e seus elementos, citando especificações, materiais e procedimentos para fundações, alvenarias, estruturas (concreto, aço e madeira), coberturas, entre outros, incluindo aspectos administrativos e de uso e ocupação do solo.

O documento australiano, Building Code of Australia, teve sua primeira versão elaborada em 1988, porém foi aplicado em caráter nacional somente em 1990. A versão seguinte foi publicada em 1996, inserindo, pela primeira vez, requisitos de desempenho para edifícios. Existe um volume do documento para edifícios comerciais e públicos e outro para habitações. Conforme ABCB (1996), o BCA possui a seguinte estrutura: objetivos, indicações funcionais, requisitos de desempenho (como segurança estrutural e ao fogo, acessibilidade, saúde e conforto), e prescrições consideradas satisfatórias para fundações, alvenarias, estruturas de aço e madeira, revestimentos, telhados, coberturas, etc. As soluções construtivas consideradas satisfatórias são aquelas que, já se sabe de antemão, atendem aos requisitos de desempenho, porém soluções inovadoras são permitidas, desde que seja comprovado o atendimento a tais exigências.

Já na França, os DTUs são estruturados em três cláusulas: técnicas, administrativas e guias. Segundo CSTB (2002), o Caderno de Cláusulas Técnicas apresenta um registro das boas práticas, com soluções consolidadas que são reconhecidamente satisfatórias. Com isso, contribui para a qualidade e a produtividade da construção de edifícios na França, para satisfazer exigências de desempenho e disseminar conhecimento. Os DTUs são subdivididos por categorias de elementos construtivos e possuem nove capítulos: campo de aplicação (objetivo e escopo), referências normativas, definições, materiais, prescrições relativas à execução, ensaios, controles, condições de início de uso, e condições de uso e manutenção. Analisando seu conteúdo, observa-se que são abordadas as principais etapas do processo de produção de edifícios, porém não são explicitadas especificações para a etapa de projeto e nem são citados requisitos de desempenho, o que difere os DTUs dos building codes estudados. O Caderno de Cláusulas Administrativas define obrigações mútuas entre as partes e deveres para com os outros participantes. Os Guias são regras de concepção de detalhes de execução, de adaptação e exemplos de soluções, podendo ter valor normativo ou informativo.

Percebe-se que tanto os Building Codes apresentados quanto os DTUs possuem em seu conteúdo aspectos administrativos. Percebe-se, também, que os "Building Codes" possuem um modelo de documento com estrutura mais complexa, geralmente com diversos itens extensos que reúnem tanto boas práticas prescritivas para as diferentes etapas do processo de produção do edifício quanto requisitos gerais de desempenho que são referência para práticas consagradas e também inovadoras. Já o DTU francês é um conjunto de uma série de documentos, cada um específico para um elemento construtivo, com subitens padronizados, o que os torna mais simples e didáticos, além de serem focados apenas em práticas consagradas.

No Brasil, ao se fazer uma análise do cenário nacional, percebe-se que não existem documentos de boas práticas nos moldes dos exemplos estrangeiros estudados. Entretanto, existem no país diversos documentos técnicos de referência elaborados por iniciativas isoladas, como empresas projetistas, construtoras ou gerenciadoras, associações e sindicatos, agentes financeiros ou financiadores de habitações, universidades e instituições de pesquisa, ou mesmo órgãos governamentais. É importante destacar que tais documentos têm objetivos muito diferentes, implicando uso e abrangência também distintos. Cada documento está em determinado contexto, associado a diferentes agentes do setor, os quais podem ter interesses específicos em cada etapa do processo de produção dos edifícios. Algumas vezes, por não haver documentos com referência nacional com objetivo único, as boas práticas que constam isoladamente em documentos podem ser conflitantes entre si ou descritas de modo parcial pelos interessados.

Para este estudo, foi feita uma pesquisa bibliográfica nacional, a partir da qual foram selecionados alguns documentos orientativos que contemplam boas práticas para a construção de edifícios, apresentados a seguir.

Existe um documento conhecido atualmente como Práticas SEAP, sob responsabilidade da então Secretaria de Estado da Administração e Patrimônio. Denominadas oficialmente de Manual de Obras Públicas - Edificações, são uma revisão das antigas Práticas DASP (do então Departamento Administrativo do Serviço Público). Estas foram publicadas pelo Decreto $\mathrm{n}^{\circ}$ 92.100, de 10 de dezembro de 1985, e ficaram vigentes até 23 de julho de 1997, quando foram republicadas como Práticas SEAP pela Portaria $n^{\circ}$ 2.296. Conforme SEAP (1997), são documentos técnicoadministrativos para: 


\begin{abstract}
[...] instituir procedimentos que consagrassem os avanços tecnológicos inerentes ao projeto, construção, manutenção e demolição de edifícios públicos; reconfigurar a estrutura das normas em três módulos específicos, compostos respectivamente pelas Práticas de Projeto, Práticas de Construção e Práticas de Manutenção; dispor sobre as atividades de manutenção, visando à preservação do desempenho $e$ prolongamento da vida útil e a redução de desperdícios e investimentos na recuperação dos edifícios públicos $e$ incorporar disposições pertinentes à economia e racionalização do uso de energia, garantia e controle da qualidade, e preservação do meio ambiente [...]
\end{abstract}

Portanto, esse documento regula as construções públicas, em âmbito federal, e aborda boas práticas de projeto, execução e manutenção dos edifícios; porém, foi instituído por instrumentos governamentais, sem a participação do setor em sua elaboração.

Outro documento, mais recente, é o Manual de Controle de Obras e Serviços da Companhia de Desenvolvimento Habitacional e Urbano do Estado de São Paulo. Conforme CDHU (2002), consiste em uma lista de verificação e controle aplicável às obras da Companhia e integrante do Sistema de Qualificação de Empresas de Serviços e Obras do Programa da Qualidade da Construção Habitacional do Estado de São Paulo (PROGRAMA..., 2003). Esse documento foi desenvolvido pelo IPT em parceria com Sindicato da Indústria da Construção Civil do Estado de São Paulo (SINDUSCON-SP), Associação Paulista de Empresários de Obras Públicas (APEOP) e Sindicato Nacional das Empresas de Arquitetura e Engenharia Consultiva (SINAENCO), considerando especificações da CDHU e normas técnicas. Portanto, foi elaborado em consenso entre agentes do setor, porém tem abrangência estadual e somente para obras da $\mathrm{CDHU}$, sendo restrito à etapa de controle de execução.

O IPT realizou outros trabalhos relativos à elaboração de documentos para construção de edifícios na década de 1980. Um deles foi desenvolvido no âmbito do Programa de Controle da Qualidade das Construções Habitacionais (PROCONTROL). Conforme IPT (1983), foram elaborados documentos de referência para edifícios habitacionais de interesse social de até quatro pavimentos, com o objetivo de orientar projetos, execução e controle das obras que utilizavam práticas convencionais. Os documentos tiveram contribuição de especialistas técnicos e foram feitos para um agente financiador de habitações (então Banco Nacional da Habitação), possivelmente para ser utilizados nos contratos com empresas projetistas e construtoras, em nível nacional. Um outro trabalho, de âmbito estadual, desenvolvido para a então Secretaria da Indústria, Comércio, Ciência e Tecnologia do Estado de São Paulo, originou documentos denominados Estudos para o Controle da Qualidade dos Componentes, Elementos e do Produto Final de Conjuntos Habitacionais. Conforme IPT (1984), eram recomendações técnicas para subsidiar as Companhias de Habitação (COHABs) na implantação de um Programa de Controle da Qualidade das obras. Incluíam recomendações para projeto, recebimento de materiais e controle da execução, cujos conteúdos baseavam-se em normas nacionais e estrangeiras e em manuais de bem construir.

Outros documentos técnicos específicos foram ainda identificados por Cleto (2006), com origem, abrangência e objetivos distintos, como, por exemplo, Cadernos de Encargos, elaborados por engenheiros especialistas da construção (COSTA, 1962; GUEDES, 2004) ou por órgãos governamentais estaduais como DOP (DEPARTAMENTO..., 1976); manuais técnicos elaborados para agentes financiadores de habitação, como PROHAB (1979) e CAIXA (2002, 2003); especificações e requisitos de desempenho de sistemas construtivos (IPT, 1998); e Procedimentos de Execução e Inspeção de Serviços de diversas construtoras e gerenciadoras existentes no país.

Como observado, apesar das características distintas dos documentos apresentados, percebe-se que a iniciativa de se elaborarem documentos técnicos de referência que descrevam boas práticas construtivas consagradas não é algo recente no Brasil. Entretanto, não há um sistema nacional para elaboração de documentos desse tipo (como os vistos nos estudos estrangeiros), nem um modelo de documento de boas práticas que possa ser utilizado como base.

\section{Proposta para elaboração de códigos de práticas no Brasil}

A partir do estudo de sistemas para a elaboração de documentos de boas práticas para a construção de edifícios, de modelos de documentos, e considerando-se a experiência profissional dos autores, desenvolveu-se uma proposta para o Brasil.

A proposta inclui aspectos institucionais, de estrutura e operacionalização do que seria um 
sistema nacional para a elaboração de documentos de boas práticas, além de um modelo para balizar a estrutura e o conteúdo dos documentos. O modelo foi aplicado a um elemento construtivo, e a proposta foi analisada junto ao setor, em reuniões e no workshop.

Primeiramente, quanto à denominação dos documentos de boas práticas brasileiros, propõe-se a terminologia Códigos de Práticas, em alusão aos Codes estrangeiros. Entretanto, é importante ressaltar que o uso do termo Código não implicaria para o Brasil documentos relacionados a leis ou decretos, nem associados à regulação ou normalização, como o é em alguns países. A proposta é traduzir o termo inglês, associado às boas práticas para a construção de edifícios, com o significado de código entendido aqui como uma coleção de regras e preceitos (FERREIRA, 1986)

Como definição dos Códigos de Práticas, propõese a apresentada por Cleto (2006, p. 145):

\section{[...] documentos técnicos de referência, não normativos, elaborados de forma consensual por agentes da cadeia produtiva $e$ unificados a nível nacional, visando à consolidação e à difusão das boas práticas para o processo de produção de edifícios, abrangendo recomendações para as etapas de projeto, execução, controle, uso e manutenção de um determinado elemento ou sistema construtivo, além de aspectos contratuais, como garantias e responsabilidades[...]}

Verificou-se que, para elaborar os Códigos de Práticas, assim como em países estrangeiros, é necessário criar um sistema de abrangência nacional que seja responsável especificamente por essa atividade, a ser realizada com a participação dos agentes da cadeia produtiva.

Propõe-se que tal sistema não seja, em princípio, vinculado à $\mathrm{ABNT}$, por se julgar que o papel inicial dos documentos de boas práticas é somente orientar o ciclo produtivo do setor da construção de edifícios (não sendo normativos) e balizar relações contratuais, considerando aspectos administrativos de garantias e responsabilidades que não fazem parte do escopo de uma norma técnica. Dessa forma, o sistema deve se interrelacionar com estruturas jurídicas existentes de modo a complementá-las, suprindo lacunas técnicas e administrativas do quadro normativo e regulatório, em âmbito nacional, sem sobreposição a nenhum sistema ou documento oficial.

A proposta é que o processo de elaboração desses documentos seja ágil e que o conteúdo seja didático para que possam ser documentos utilizados também em treinamentos de profissionais e formação acadêmica. Posteriormente, quando o setor já tiver absorvido o uso dos documentos, estes podem passar por um processo similar ao ocorrido com os DTUs na França, ou seja, ser incorporados ao sistema normativo.

Analisando os sistemas estrangeiros estudados, considera-se que o mais próximo do atual cenário nacional é o modelo francês, inclusive quanto ao alinhamento dos programas da qualidade da construção civil entre os dois países (sabe-se que a criação do PBQP-H teve como inspiração o programa francês QUALIBAT - Qualification et Certification des Entreprises $d u$ Bâtiment). Também foram inspirados no modelo francês a criação do SiNAT no Brasil e a de seu respectivo documento de avaliação técnica (DATec), para produtos inovadores.

Assim, propõe-se que o sistema nacional para a elaboração de documentos de boas práticas tenha como base o modelo francês e que seus respectivos documentos (Códigos de Práticas) tenham como referência os DTUs. A proposta, portanto, considera que o sistema nacional também seja inicialmente integrado ao PBQP-H, funcionando em paralelo aos demais sistemas nacionais já existentes no Programa.

Propõe-se, ainda, identificar o novo sistema pela sigla SiNCOP, cujo significado é Sistema Nacional de Códigos de Práticas para produtos convencionais da construção de edifícios. Assim, o SiNCOP, com a elaboração e a disseminação das boas práticas consagradas, complementa os temas já abordados pelo PBQP-H, quais sejam: Sistema de Avaliação da Conformidade de Empresas de Serviços e Obras (SiAC), Sistema de Avaliação da Conformidade de Materiais, Componentes e Sistemas Construtivos (SiMAC) e o já citado SiNAT.

Considera-se que a criação de um sistema nacional desse tipo seja um mecanismo de interesse público, o que sugere que seja conduzido por uma instância governamental, mas com participação ativa de agentes privados, indo também ao encontro do conceito do PBQP-H. O modelo francês é fundamentado na existência de comissões com representantes públicos e privados, mesmo princípio adotado nos demais países estudados. Propõe-se, portanto, adotar tal estrutura para o sistema brasileiro, com a participação voluntária dos diferentes agentes do setor da construção de edifícios.

No modelo francês, o texto de referência dos DTUs é elaborado por profissionais do CSTB e analisado por comissões, com representantes do 
setor, para obter o consenso a respeito do documento. Entretanto, sabe-se que no Brasil seria difícil ter uma única instituição responsável pela elaboração dos diversos textos que dariam origem aos Códigos de Práticas. Portanto, propõe-se que tais textos de referência sejam elaborados e analisados por Grupos de Trabalho (GTs), em reuniões técnicas, até se obter o consenso. Propõese que cada GT seja responsável por um texto de um futuro Código de Prática e que, portanto, contenha representantes do setor que incluam especialistas técnicos com conhecimento relativo ao elemento construtivo em questão.

Em função das demandas do SiNCOP, novos GTs vão sendo criados, sendo cada um deles voltado a um elemento construtivo do edifício. Entretanto, como se trata de um sistema único, é necessário que as atividades de todos os GTs sejam coordenadas por uma única representação, visando a resultados harmonizados, ou seja, Códigos de Práticas que não tenham conflito entre si, nem sobreposições, por exemplo. Para tanto, propõe-se a criação de um Comitê Técnico do SiNCOP, o qual seria responsável por analisar o trabalho dos diferentes GTs, harmonizando e integrando os diferentes textos de Códigos de Práticas entre eles e deles com os demais Códigos de Práticas já existentes.

Propõe-se que os textos dos Códigos de Práticas, depois de obtido consenso nos GTs e harmonização no Comitê Técnico, tornem-se aptos para a publicação formal somente após a aprovação da Comissão Nacional do SiNCOP, instância esta a ser criada nos moldes das Comissões Nacionais dos demais sistemas do PBQP-H. A Comissão Nacional seria também responsável por autorizar a criação dos GTs, contando com o apoio de uma secretaria técnicoadministrativa, a qual a auxiliaria e às demais instâncias do SiNCOP.

A partir do engajamento do setor e do aumento da demanda para elaborar Códigos de Práticas, a estrutura do SiNCOP pode ser incrementada, por exemplo, constituindo-se Comitês Técnicos Específicos, cujos trabalhos seriam harmonizados por um único Conselho Técnico, conforme a Figura 1.

Considera-se que detalhes da proposta de operacionalização do SiNCOP e suas atribuições administrativas não fazem parte do escopo técnico e científico deste artigo. Ressalta-se, porém, que a proposta completa já foi apresentada para o PBQP$\mathrm{H}$, como uma Minuta de Regimento do SiNCOP, e para representantes do setor produtivo, durante o workshop.

A proposta do modelo de documento para a elaboração de Códigos de Práticas foi feita a partir dos documentos estudados. Foram observados dois principais tipos de estrutura de documento: subdividido em etapas do processo de produção do edifício (cada etapa contempla diferentes elementos construtivos); e subdividido em elementos construtivos (as diversas etapas são consideradas para cada elemento construtivo).

Verificou-se que, em geral, os building codes possuem parte de sua estrutura subdividida em elementos construtivos e o restante em requisitos de desempenho. Já os DTUs possuem sua estrutura subdividida somente em elementos construtivos. Portanto, propõe-se que o modelo de Código de Práticas para o Brasil também se baseie na estrutura subdividida em elementos construtivos, o que continua mantendo a proposta alinhada com o modelo francês. Entretanto, especificações de projeto e requisitos de desempenho não constam nos DTUs, sendo itens contemplados apenas nos building codes. Por se julgar essencial que um Código de Práticas nacional aborde tais aspectos, propõe-se incluí-los no documento.

Portanto, cada Código de Práticas é elaborado para um elemento construtivo e deve contemplar todas as etapas do processo de produção do edifício, atentando-se para que não haja informações conflitantes entre as etapas. Deve, ainda, incluir aspectos administrativos e contratuais, como em todos os documentos estrangeiros estudados. 


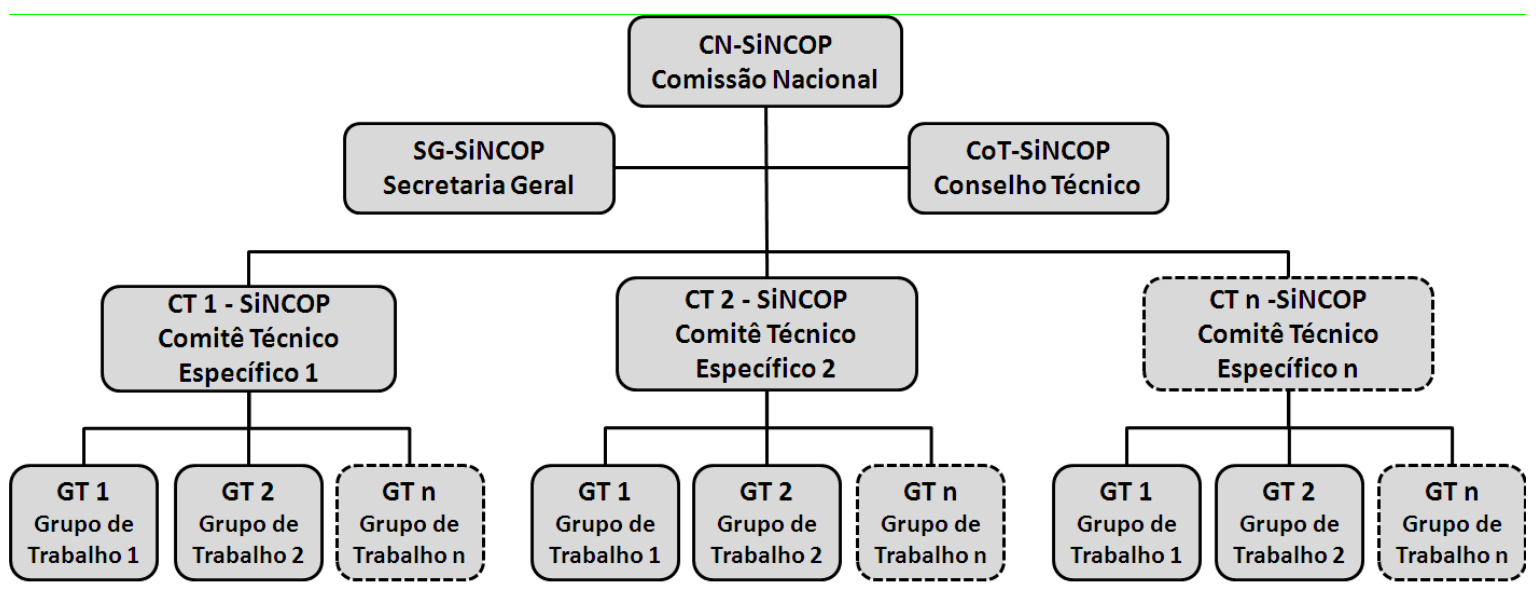

Figura 1 - Estrutura proposta para o SiNCOP

Em relação a seu conteúdo, propõe-se que o documento se inicie com um item introdutório, como em todos os documentos estrangeiros, incluindo objetivos e escopo de sua aplicação, bem como restrições de uso, além das terminologias e definições. $\mathrm{O}$ item seguinte, considerando a sequência das etapas, seria o referente à etapa de projeto, com especificações técnicas e requisitos de desempenho considerados no projeto do elemento construtivo para que o edifício tenha adequado desempenho em sua vida útil.

As demais etapas seguem a sequência dos DTUs. A seguir, tem-se a etapa de seleção de materiais empregados no elemento construtivo, com especificações, indicação de ensaios e avaliações técnicas (no Brasil, poderia ser feita referência a Programas Setoriais da Qualidade, incentivando o uso de materiais previamente avaliados e qualificados), e procedimentos para recebimento dos materiais em obra.

Posteriormente, tem-se a etapa de execução, descrevendo-se boas práticas construtivas e procedimentos executivos. É importante apresentar um subitem que apresente os controles do processo de produção. Propõe-se que, quando for o caso, se inclua também um subitem sobre a mão de obra, abordando determinadas competências que operários devem ter para executar serviços relativos ao elemento construtivo conforme as boas práticas recomendadas no documento. A capacitação da mão de obra não é apresentada em nenhum dos documentos estrangeiros estudados, porém se considera essencial no cenário nacional.

Na sequência, há as boas práticas para as etapas de entrega do edifício e para as etapas de uso e manutenção. Em seguida, propõe-se apresentar o item com aspectos administrativos e contratuais de garantias e responsabilidades dos envolvidos. As referências bibliográficas utilizadas na elaboração dos Códigos de Práticas devem ser citadas no final deles.

A partir desse modelo de documento proposto foi elaborado um texto-base para um Código de Prática para alvenaria de vedação de blocos cerâmicos. A seguir, foi constituído um Grupo de Trabalho para analisar o documento, buscando o consenso a respeito de seu conteúdo. Participaram do GT associações técnicas e sindicatos representantes da indústria cerâmica, como a Associação Nacional da Indústria Cerâmica, o Sindicato da Indústria da Cerâmica para Construção do Estado de São Paulo e a Associação das Cerâmicas Vermelhas de Itu e Região, além de entidades como CAIXA, CDHU, SECOVI-SP, SINDUSCON-SP, entre outras, bem como empresas especializadas em projeto e execução de alvenarias. Após nove reuniões técnicas desse GT, foi obtido consenso entre seus membros, o que deu origem à versão final do Código de Prática para alvenaria de vedação de blocos cerâmicos (IPT, 2011).

Essa proposta de Código de Prática, bem como as propostas do SiNCOP e de seu modelo de documento foram apresentados no workshop, cujo objetivo era difundir tais propostas e discuti-las com outras entidades representativas do setor da construção de edifícios no Brasil. O resultado foi a validação das propostas pelos presentes, com uma série de contribuições, a seguir relatadas.

Quanto ao SiNCOP, considerou-se interessante sua inserção no PBQP-H, uma vez que assegura sua validade nacional e mantém a representatividade do setor na elaboração dos documentos, melhorando o diálogo entre agentes da cadeia produtiva e auxiliando na verificação da conformidade dos materiais, componentes, elementos e sistemas construtivos. Considerou-se que os objetivos dos Códigos de Práticas eram 
realmente diferentes dos objetivos das Normas Técnicas e sugeriu-se que o escopo desses documentos fosse bem definido, para não haver interferências.

Quanto aos documentos apresentados, considerouse que eram inteligíveis, claros e fáceis de ser utilizados, inclusive no canteiro de obras, para verificações na etapa de execução dos edifícios. Sugeriu-se inserir índices de produtividade, práticas de segurança do trabalho específicas para cada elemento construtivo (complementando a NR-18) e práticas ambientais (análise de ciclo de vida, encaminhamento de resíduos, etc.). Ressaltou-se que todas as práticas apresentadas nos Códigos de Práticas devem ser baseadas em estudos técnicos e experiências comprovadas, sem interesses específicos, sendo também compatíveis com as Normas. Recomendou-se que cada estado complementasse os Códigos de Práticas com aspectos regionais específicos e, ainda, que os GTs atualizassem os documentos constantemente, para evitar o registro de boas práticas obsoletas e a exclusão de determinados tipos de produtos.

Quanto ao uso dos Códigos de Práticas, sugeriu-se:

(a) incorporá-los aos diversos contratos;

(b) utilizá-los também na autogestão das construções, além do mercado formal; e

(c) mencioná-los nos processos de licitação de obras públicas, no intuito de considerar também as boas práticas construtivas, além do critério preço.

Considerou-se, ainda, a distribuição dos Códigos de Práticas pelos fabricantes de materiais como recomendação de uso de seus respectivos produtos; e a utilização dos documentos nos treinamentos para capacitação da mão de obra oferecidos pelo Serviço Nacional de Aprendizagem Industrial (SENAI), qualificando profissionais para executar as boas práticas recomendadas. Sugeriu-se também que os agentes financiadores de habitação solicitem o atendimento aos Códigos de Práticas para assegurar a qualidade dos empreendimentos.

Constatou-se que as propostas foram aceitas pelos representantes do setor da construção de edifícios, que ressaltaram, inclusive, a importância do registro do conhecimento técnico e sua homogeneização no país, auxiliando no ensino dos jovens recém-formados e na atualização dos profissionais experientes. Obteve-se, ainda, no workshop, o apoio das instituições para a continuidade dos trabalhos em torno da ideia da elaboração de Códigos de Práticas, como ação compartilhada pelos agentes da cadeia produtiva.

\section{Considerações finais}

A proposta de um modelo de documento para elaborar um Código de Prática, o desenvolvimento de um Código de Prática para alvenaria de vedação de blocos cerâmicos e a proposta de estrutura e funcionamento de um sistema nacional para elaborar tais documentos (SiNCOP) foram os principais resultados desta pesquisa, contribuindo com o avanço e a disseminação do tema no país. A proposta foi validada junto ao setor produtivo, que manifestou interesse e apoio à continuidade dos trabalhos, apresentando contribuições importantes a serem incorporadas na proposta. Considera-se, portanto, que os objetivos do trabalho foram atendidos, com escopo que abrange somente o setor da construção de edifícios. Entretanto, ressalta-se que, a partir de pesquisas complementares, torna-se possível estender o tema, de modo a envolver todo o macrocomplexo construção.

Como desdobramento da pesquisa, verificou-se que, com o auxílio da Tecnologia da Informação e Comunicação (TIC) aplicada à construção, alguns países já criaram ferramentas de informática que automatizassem o sistema de verificação de conformidade de cada projeto de edifício com seus respectivos Building Codes, processo este denominado Code Checking System. Os EUA, por exemplo, desenvolveram recentemente o SMARTcodes, cujo objetivo é transformar os Building Codes em uma linguagem interpretável pelo computador para automatizar a análise de projetos de edifícios. Na Austrália, o Cooperative Research Centre for Construction Innovation, em parceria com entidades como ABCB, CSIRO e Universidade de Sydney, também desenvolveu uma ferramenta para realizar avaliação automatizada de projetos apresentados no modelo BIM (Building Information Modeling) utilizandose as exigências definidas no Building Code of Australia (EASTMAN et al., 2009; CHOI; KIM, 2008).

No Brasil, uma ferramenta desse tipo poderia ser inicialmente utilizada em verificações preliminares para as quais já existam regulamentações, como para o uso e ocupação do solo dos municípios. Posteriormente, implantados os Códigos de Práticas, pode-se estender a verificação automática dos projetos com tais documentos. Atualmente, a maioria dos projetos de edifícios no país ainda não é feita no modelo BIM; entretanto, essa é uma realidade que já está mudando. Fato é que a Comissão da ABNT CEE134 - Modelagem de Informação da Construção já está desenvolvendo uma norma para o sistema de classificação da 
informação da construção (ABNT, 2011), o que irá contribuir para a consolidação do BIM no país.

Além disso, para a organização das informações nos documentos que integram os Codes Checking Systems, tem sido adotado um modelo de visão facetada, em substituição à classificação hierarquizada de temas, cujo melhor exemplo é o sistema OmniClass ${ }^{\mathrm{TM}}$ gerenciado pelo Construction Specification Institute (OMNICLASS, 2011). Assim, tal classificação também poderia ser considerada, em momento oportuno, para aprimorar a organização da estrutura e o detalhamento do conteúdo dos Códigos de Práticas no Brasil.

Como perspectiva para implantação dos Códigos de Práticas no Brasil, o setor citou a relevância do tema em razão do aumento significativo da construção de habitações, devido ao Programa "Minha Casa, Minha Vida" do Governo Federal, sugerindo a elaboração de outros Códigos de Práticas, tais como alvenaria estrutural de blocos cerâmicos e alvenaria estrutural de blocos de concreto e estruturas de aço. Para tanto, é importante que associações e sindicatos representantes de subsetores de outros elementos construtivos tenham iniciativa para elaborar seus Códigos de Práticas e participem dos Grupos de Trabalho. Ou seja, considera-se essencial mobilizar agentes da oferta e da demanda do setor para a continuidade do sistema.

Sabe-se, entretanto, que implantar um sistema para elaboração de Códigos de Práticas no Brasil será um processo demorado, haja vista que o sistema nos EUA demandou dezenas de anos para sua consolidação no ICC. Pretende-se, porém, que a proposta deste artigo, considerando a atualidade da discussão do tema, seja um passo para esse grande desafio, o qual é uma contribuição importante e necessária para a modernização da construção no Brasil.

\section{Referências bibliográficas}

AUSTRALIAN BUILDING CODES BOARD (ABCB). Building Code of Australia. Canberra: Board, 1996. 52 p.

ASSOCIAÇÃO BRASILEIRA DE NORMAS

TÉCNICAS. Home. Disponível em:

<http://www.abnt.org.br>. Acesso: 15 dez. 2009.

ASSOCIAÇÃO BRASILEIRA DE NORMAS TÉCNICAS. Sistema de Classificação da Informação da Construção: parte 1: terminologia e classificação. Rio de Janeiro, 2011.
BARROS, M. M. B. Aprovações Técnicas, Qualidade de Laboratórios e Aperfeiçoamento da Normalização Técnica: relatório de estágio. Cooperação Técnica Brasil/França/BID para o PBQP-H, 2000.

BRITISH STANDARDS INSTITUTION (BSI).

National Standards. Disponível em: < http://www.bsigroup.com/en/Standards-andPublications/About-standards/Productdefinitions/>. Acesso: 18 jan. 2011.

CAIXA Econômica Federal. Manual Técnico de Engenharia: orientação para apresentação de empreendimentos habitacionais do setor privado, 2002.

CAIXA Econômica Federal. Alvenaria Estrutural: materiais, execução da estrutura e controle tecnológico. In: CAIIXA Econômica Federal.

Requisitos e Critérios Mínimos para Solicitação de Financiamento de Edifícios em Alvenaria Estrutural. 2003. Disponível em:

<https://webp.caixa.gov.br/urbanizacao/inovacoes/ alvenaria.asp>. Acesso em: 20 mar. 2011.

CHOI, J.; KIM, I. An Approach to Share Architectural Drawing Information and Document Information for Automated Code Checking System. Tsinghua Science and Technology, v. 13, n. S1, p. 171-198, out. 2008.

COMPANHIA de Desenvolvimento Habitacional e Urbano do Estado de São Paulo (CDHU).

Manual de Controle de Obras e Serviços. 2002. Disponível em: <http://www.cdhu.sp.gov.br>. Acesso em: 19 mar. 2011.

CLETO, F. R. Referenciais Tecnológicos para a Construção Civil. 2006. São Paulo. Dissertação (Mestrado em Engenharia Civil) - Escola Politécnica, Universidade de São Paulo, São Paulo, 2006.

COSTA, P. Caderno de Encargos para a Construção de Edifícios. Rio de Janeiro: Científica, 1962.

CENTRE SCIENTIFIQUE ET TECHNIQUE DU BATIMENT ET LA DIRECTION GENERALE DE L'URBANISME, DE L'HABITAT ET DE LA CONSTRUCTION. Décision $\mathbf{n}^{\circ}$ M0127, BRESIL: Assistance Pour la Conception et l’Élaboration des Éléments Constitutifs de DTU. 2002.

DEPARTAMENTO DE EDIFÍCIOS E OBRAS PÚBLICAS DA SECRETARIA DOS SERVIÇOS

E OBRAS PÚBLICAS DO GOVERNO DO

ESTADO DE SÃO PAULO. Caderno de

Encargos de Edificações. São Paulo, 1976. 
EASTMAN. C. M. et al. Automatic Rule-Based Checking of Building Designs. Automation in Construction, v. 18, n. 8, p. 1011-1033, 2009.

ESCOLA POLITÉCNICA DA UNIVERSIDADE DE SÃO PAULO. Estrutura Metodológica e Institucional para Desenvolvimento, Aplicação e Difusão de Referenciais Tecnológicos. São Paulo: Programa Habitare/FINEP, 2010.

FERREIRA, Aurélio Buarque de Holanda. Novo Dicionário da Língua Portuguesa. Editora Nova Fronteira, 1986.

GUEDES, M. F. Caderno de Encargos. 4.ed. São Paulo: PINI, 2004.

\section{INTERNATIONAL CONFERENCE OF} BUILDING OFFICIALS. Uniform Buiding Code. 3.ed. Whittier: ICBO, 1994.

INTERNATIONAL CODE COUNCIL. International Building Code. Upper Montclair: ICC, 2000.

INSTITUTO DE PESQUISAS TECNOLÓGICAS DO ESTADO DE SÃO PAULO. Programa de Controle da Qualidade das Construções Habitacionais (PROCONTROL). RT n ${ }^{\circ} 17985$, 1983.

INSTITUTO DE PESQUISAS TECNOLÓGICAS DO ESTADO DE SÃO PAULO. Estudos para o Controle da Qualidade dos Componentes, Elementos e do Produto Final de Conjuntos Habitacionais. São Paulo: IPT, 1984.

INSTITUTO DE PESQUISAS TECNOLÓGICAS DO ESTADO DE SÃO PAULO. Critérios Mínimos de Desempenho para Habitações Térreas de Interesse Social. São Paulo: IPT, 1998.

INSTITUTO DE PESQUISAS TECNOLÓGICAS DO ESTADO DE SÃO PAULO. Elaboração e Implementação de Referenciais Tecnológicos para Elementos Construtivos de Edifícios Habitacionais de Interesse Social. São Paulo: Programa Habitare/FINEP, 2010.
INSTITUTO DE PESQUISAS TECNOLÓGICAS DO ESTADO DE SÃO PAULO. Códigos de Práticas na Construção Civil. Disponível em: <http://www.ipt.br/projeto/2codigos_de_praticas_na_construcao_civil.htm>. Acesso: 11 abr. 2011.

NATIONAL RESEARCH COUNCIL OF CANADA. National Building Code of Canada. Canadá, 2005.

OMNICLASS ${ }^{\mathrm{TM}}$. OmniClass Construction Classification System. Disponível em: <www.omniclass.org>. Acesso: 12 fev. 2011.

PROGRAMA Brasileiro da Qualidade e Produtividade do Habitat. Regimento Geral do Sistema Nacional de Avaliações Técnicas de produtos inovadores. 2007. Disponível em: <http://www2.cidades.gov.br/pbqph/projetos_sinat.php>. Acesso em: 09 nov. 2010.

PROHAB. Manuais de Procedimentos para Planejamento, Projeto, Execução e Avaliação da Habitação. São Paulo: IPT, 1979.

PROGRAMA da Qualidade da Construção Habitacional do Estado de São Paulo (QUALIHAB). Regimento de Qualificação de Sistemas do Programa da Qualidade da Construção Habitacional do Estado de São Paulo. 2003. Disponível em: <http://portalshcdhu.cdhu.sp.gov.br/http/qualihab/ abertura/teabertura.asp >. Acesso em: 15 nov. 2010.

\section{SECRETARIA DE ESTADO DA} ADMINISTRAÇÃO E PATRIMÔNIO. Práticas da SEAP: projeto, construção e manutenção. 1997. Disponível em: <http://www.comprasnet.gov.br/publicacoes/manu al.htm>. Acesso em: 09 nov. 2010.

\section{Agradecimentos}

Os autores agradecem à Financiadora de Estudos e Projetos (FINEP), pelo financiamento do projeto de pesquisa que deu origem a este artigo.

Revista Ambiente Construído

Associação Nacional de Tecnologia do Ambiente Construído

Av. Osvaldo Aranha, $99-3^{\circ}$ andar, Centro

Porto Alegre - RS - Brasil CEP $90035-190$

Telefone: +55 (51) 3308-4084

Fax: +55 (51) 3308-4054

www.seer.ufrgs.br/ambienteconstruido

E-mail: ambienteconstruido@ufrgs.br 